\title{
Os Desafios na Utilização do Laboratório de Ensino de Ciências pelos professores de Ciências da Natureza
}

\author{
The Challenges in the Use of the Science Teaching Laboratory by Nature \\ Science Teachers
}

\begin{abstract}
Francisca Helen Cardoso Gonçalves (helengoncalves.hcs@gmail.com) Universidade Federal de Juiz de Fora (UFJF)
\end{abstract}

\author{
Ana Carolina Araújo da Silva (anacarolina.silva@ufjf.edu.br) \\ Universidade Federal de Juiz de Fora (UFJF) \\ Luisa Gomes de Almeida Vilardi (luisavilardi@gmail.com) \\ Universidade Federal de Juiz de Fora (UFJF)
}

\begin{abstract}
Resumo: Este trabalho é um recorte de uma pesquisa de mestrado, e tem o objetivo de compreender a utilização do laboratório de Ciências de uma escola estadual do Ceará. Os sujeitos desta pesquisa foram onze professores da área de Ciências da Natureza do Ensino Médio e membros do núcleo gestor - um diretor e três coordenadores escolares. A inclusão do núcleo gestor é por serem os representantes da comunidade escolar junto à Secretaria de Educação do Estado. Desta forma, recorremos à metodologia de pesquisa de cunho qualitativo, tendo como instrumentos de coleta de dados: questionário para os professores e entrevista semiestruturada para os membros do núcleo gestor. $\mathrm{Na}$ análise, identificamos categorias referentes ao uso do laboratório que são: a estrutura da escola e do laboratório e como os professores utilizam o laboratório. Em relação a estrutura do Laboratório de Ciências, identificamos a precariedade do espaço, mas em processo de revitalização. Observamos também que existe a necessidade de formação continuada relacionada às atividades experimentais, tanto para sensibilização, quanto para elaboração e realização destas atividades. Destarte, que este estudo foi realizado na escola em que a pesquisadora trabalha como professora de Física, tornando-se de considerável interesse para a reflexão de suas práticas pedagógicas.
\end{abstract}

Palavras-chave: Atividades Práticas e Experimentais; Ensino de Ciências da Natureza; Laboratório de Ciências.

Abstract: This work is a master's research resource, and aims to understand the use of the science laboratory of a state school in Ceará. The subjects of this research were eleven teachers in the area of Natural Sciences in High School and the members of the managing nucleus - a director and three school coordinators. The inclusion of the management nucleus is because they are the representatives of the school community with the State Department of Education. Thus, we used the qualitative research methodology, using data collection instruments: questionnaire for teachers and semistructured interview for the members of the management group. In the analysis, we identified categories related to the use of the laboratory, that are: the structure of the school and the laboratory and how teachers use the laboratory. In relation to the structure of the Science Laboratory, we identified the precariousness of the space, but in 
the process of revitalization. We also observed that there is a need for continuing training related to the experimental ones, both for sensitization, and for the elaboration and realization of these activities. Thus, this study was conducted at the school where the researcher works as a physics teacher, becoming of considerable interest for the reflection of her pedagogical practices.

Keywords: Practical and experimental activities. Science Education Teaching. Science Laboratory.

\section{INTRODUÇÃO}

Este artigo faz parte de um recorte de dissertação de mestrado desenvolvido no Programa de Pós-Graduação em Gestão e Avaliação da Educação Pública e se justifica pela necessidade de compreender os desafios na utilização do laboratório de ciências pelos professores de Ciências da Natureza, de uma escola pública estadual do Ceará. Nesta pesquisa, considera-se a importância das atividades práticas experimentais como propícias à concretização da compreensão dos conceitos pertinentes a área das Ciências da Natureza pelos estudantes. A idealização desse estudo iniciou-se a partir das percepções de possíveis dificuldades entre os professores no tocante à realização de aulas práticas e experimentais no laboratório de ciências desta escola. Outra justificativa para este estudo foi a indisponibilidade do laboratório de ciências a que se designa, pois nem sempre estava possibilitado para o agendamento e execução das aulas planejadas, ou apresentava escassez de alguns materiais necessários, dentre outros motivos. Por esta razão, acredita-se que investigar o laboratório de ciências envolve evidenciar as possibilidades e limitações no uso desse espaço e o desenvolvimento das atividades experimentais.

As atividades práticas e experimentais têm sua relevância principalmente por possibilitarem a construção do conhecimento a partir de sua relação com o dia a dia dos alunos. Admite-se que estas atividades favorecem a participação do aluno à medida que o estimula, permitindo-lhe maior contato e interação com os materiais dispostos, exploração da sua curiosidade, exercendo seu protagonismo no processo de ampliação e consolidação de seus conhecimentos.

Assim, os laboratórios de Ciências têm sido considerados como um importante espaço para o desenvolvimento de aulas experimentais e essencial pelo fato de proporcionar observação e estimular o interesse dos alunos (BLOSSER, 1988). Nestes ambientes, alguns objetivos têm a possibilidade de serem mais facilmente atingidos, tais 
como: habilidades em manipular, investigar, questionar, comunicar; habilidades cognitivas (pensamento crítico, análise, síntese); compreensão da natureza da ciência, multiplicidade de métodos científicos, interrelações entre ciência e tecnologia; atitudes como curiosidade, confiança, perseverança, responsabilidade, colaboração, até o gosto pela disciplina (TRAVERS, 1973, apud BLOSSER, 1988). Este espaço diferenciado da sala de aula possibilita ainda estimular a participação do estudante, por permitir maior contato deste com os materiais dispostos, explorando sua curiosidade, fazendo o aluno exercer seu protagonismo no processo de ampliação e apropriação de seus conhecimentos.

Entendemos que a escola tem o compromisso de promover a autonomia do aluno, fazendo com que este tenha significativa participação na consolidação de seu aprendizado, fundamentando e defendendo suas ideias, mas com devido apreço e deferência às ideias divergentes. Nesse sentido, o foco deste trabalho é compreender como o laboratório de ciências de uma escola estadual do Ceará vem sendo utilizado pelos professores de Ciências da Natureza. Os participantes da pesquisa desta pesquisa são os professores e o núcleo gestor da unidade escolar.

\section{A EXPERIMENTAÇÃO E O ENSINO DE CIÊNCIAS}

Considerando as formações inicial e continuada dos professores, principalmente das disciplinas das Ciências da Natureza bem como de Matemática, Gouveia (2017) explora a necessidade de modificações de metodologias de ensino e da utilização de ferramentas pedagógicas diversificadas, haja vista situações em que a ciência e a tecnologia participam do cotidiano. $O$ autor afirma ser a atividade docente uma permanente busca pelo conhecimento, tanto o conhecimento a ser ensinado, quanto o conhecimento necessário para o aperfeiçoamento da própria ação junto aos alunos.

As atividades práticas ${ }^{1}$ são ferramentas pedagógicas que podem contribuir para os alunos se relacionarem de maneira distinta com os fenômenos estudados, atrelando prática e teoria em um mesmo contexto pedagógico. O laboratório, por sua vez, tem sido considerado um eminente meio no processo de Ensino de Ciências (BLOSSER,1988), diante de sua destinação, que é a realização de atividades

\footnotetext{
${ }^{1}$ Bassoli (2014, apud Campos e Nigro, 1999) diferencia as modalidades de atividades práticas em: (i) demonstrações práticas; (ii) experimentos ilustrativos; (iii) experimentos descritivos, e (iv) experimentos investigativos. Neste artigo, utilizamos o termos atividades experimentais.
} 
experimentais $^{2}$. Borges (2002) menciona que o trabalho no laboratório pode ser organizado de diversas maneiras e apresenta diferentes alternativas para as atividades prático-experimentais, que são: estruturar as atividades de laboratório como investigações ou problemas práticos mais abertos e atividades que envolve o uso de simulações em computador e os laboratórios investigativos baseados em computadores combinados com sensores de vários tipos.

Para que a aprendizagem seja mais significativa para o aluno, ela deve atrelar o conhecimento científico com o cotidiano do aluno, dialogando com seu contexto de vida e integrando-o a novas possibilidades de pensar e compreender a realidade. Além disso, Gouveia (2017) identifica algumas ênfases e concepções de leitura e compreensão do mundo como sendo imprescindíveis ao letramento científico dos estudantes, que contempla suas atitudes de participação e que os instrui a explorar as ciências com competências além da simples assimilação de conteúdos, para a realidade cotidiana da sociedade.

Ainda de acordo com Gouveia (2017), as atividades experimentais têm sua relevância tanto para a consolidação do aprendizado quanto para a socialização dos atores envolvidos, pois estimula o diálogo, a discussão de dados e evidências, facilitando a interação entre os alunos e o professor. Gonçalves e Marques (2006) direcionou seu trabalho para a preocupação em apontar possibilidades de desenvolvimento de atividades práticas e experimentais. No entanto, julga-se como necessária a revisão e a reavaliação da prática docente para se tentar obter sucesso na melhora e na inovação das metodologias aplicadas, principalmente em relação às propostas de situações didáticas desafiadoras que estimulem o aluno a elaborar hipóteses, em favor da aproximação do conhecimento científico às vivências com a natureza e promoção de autonomia discente, em busca do protagonismo estudantil.

Nesse âmbito, Cachapuz et al. (1989) verifica fatores relacionados à formação dos professores, incluindo certas dificuldades, consideradas como impedimentos por alguns, e uma indispensável reflexão contínua do processo de ensino e aprendizagem, sugerindo que é no início de sua atividade profissional que os professores (de Física e Química) mais usam quaisquer dos tipos de trabalho experimental. Também traz a formação do professor como oportunidade de reflexão sobre a participação do trabalho

\footnotetext{
${ }^{2}$ Em algumas escolas o laboratório de ciências tem servido como depósitos, sala de apoio ou atividades que não envolve a utilização do laboratório (GONÇALVES, 2019).
} 
experimental no desenvolvimento do processo de ensino e aprendizagem das ciências naturais, bem como a maneira de se organizar e se ofertar esse tipo de metodologia no ensino médio, os objetivos do trabalho experimental e o papel do professor para tal desenvolvimento. Portanto, é apontada a necessidade de formação continuada (após 5 anos, por exemplo), reiterando que alguns professores podem não ter tido oportunidade de familiarização com trabalhos experimentais. Essa realidade pôde ser verificada na escola em estudo, diante do seu quadro de professores de Ciências da Natureza e seus tempos de atuação no ensino.

Analogamente, Galiazzi et al. (2001) discute as resistências atitudinais, exemplificadas na conduta dos alunos quando são solicitados a agir de forma diferente do que foram acostumados - essencialmente executar tarefas para a aprovação - e assim uma parcela deles, durante a disciplina, se comporta no modelo tradicional e apenas cumpre tarefas. Alguns estudantes têm dificuldades de entender o propósito das atividades experimentais. A autora fomenta que tais resistências são constituintes das possibilidades da aprendizagem. Isso significa que atentar a elas facilita o entendimento do modelo pedagógico do professor (GALIAZZI et al., 2001). Novamente, volta-se um olhar para o modelo de professor tradicional, ainda presente na escola em estudo. Isso posto, Thomaz (2000) aponta para a ampliação dos tradicionais objetivos para o ensino de ciências, na tentativa também de resgatar docentes desprovidos destas oportunidades quando da sua formação inicial.

Analisando as atividades experimentais por suas especificidades, Borges (2002) relaciona seus objetivos à superação das dificuldades de aprendizagem dos estudantes, bem como concepções equivocadas sobre a natureza desse processo. Isso refere-se ao envolvimento comprometido com a busca de soluções bem articuladas para as situações-problema propostas, tornando-se mais importantes que a simples manipulação de objetos. $\mathrm{O}$ estudo discute acerca de que os estudantes deveriam conhecer alguns dos principais produtos das Ciências da Natureza, ter experiências com eles, compreender os métodos utilizados pelos cientistas para a produção de novos conhecimentos, e como a ciência é uma das forças transformadoras do mundo, exibindo uma postura necessária anterior à atividade prática. Entretanto, salienta-se a disposição das escolas com relação a equipamentos e laboratórios, como também a sua não utilização, e algumas de suas causas, mencionando o fato de não existirem atividades previamente estruturadas para 
uso do professor, falta de tempo para planejar a realização de atividades como parte do seu programa de ensino, laboratório fechado e sem manutenção (BORGES, 2002).

No âmbito do exercício profissional, Cachapuz et al. (1989) explana persuasiva ilustração sobre a importância dada aos trabalhos experimentais nas aulas por professores, quando expõe que a maioria dos professores envolvidos utilizam este tipo de atividade frequentemente ou de vez em quando nas suas aulas. $\mathrm{O}$ fato dos trabalhos experimentais não serem consenso como as atividades realizadas em sala de aula pode estar relacionado, inclusive, às condições de trabalho existentes na escola. Esse fator é considerado essencial a constar na pesquisa em execução.

Numa proposta com contexto do ensino por investigação, os professores atuam como mediadores do processo, essencialmente na condução das interações discursivas. Salienta-se que não se deve desprezar os conhecimentos prévios trazidos pelos alunos, assim como a valorização da problematização, mas ainda há entraves na rotina profissional de muitos professores, no tocante à tal metodologia de ensino. Diante do exposto, Leite et al. (2019) afirmam que uma formação continuada deve comprometerse a ouvir os anseios e dificuldades dos(as) docentes, compartilhando a proposição de novas formas de ensinar, na tentativa de uma formação integradora e que proporcione uma reflexão acerca da prática e interlocução entre os conhecimentos científicos no sentido de aprimorá-los.

Não obstante, diante do exposto até então, se permite relacionar a situação de formação docente, seu tempo de atuação, o aporte significativo na formação dos estudantes, tanto no âmbito escolar quanto social.

\section{METODOLOGIA}

Esta pesquisa buscou compreender como o laboratório de Ciências vem sendo utilizado pelos professores de Ciências da Natureza na EEFM Heráclito de Castro e Silva. A presente pesquisa foi desenvolvida pela professora-pesquisadora, que tem a escola como o seu campo de trabalho e de pesquisa. Ao investigar o laboratório de ciências da referida escola, a professora-pesquisadora buscou contribuir para a compreensão e possibilidades que esse espaço poderia proporcionar para o desenvolvimento de atividades experimentais nas aulas de Ciências da Natureza. Para atingir os objetivos desta pesquisa, a opção metodológica abordada é qualitativa, 
entendida como aquela em que a fonte direta dos dados é o próprio ambiente natural, constituindo o investigador o instrumento principal (LUDKE e ANDRÉ, 1986). A pesquisa qualitativa foi priorizada por apontar caráter descritivo, atenta ao processo como um todo e não somente por seus resultados, conduzindo-se a uma análise de dados de forma indutiva, pois seu significado tem grande importância neste tipo de abordagem deste estudo de caso (BOGDAN e BIKLEN, 1994).

A metodologia, desta pesquisa, envolveu compreender como os sujeitos ${ }^{3}$ da pesquisa têm percebido e utilizado o laboratório de Ciências. Para isso, foi utilizado como instrumentos de coleta de dados questionários e entrevistas. Todavia, é importante ressaltar que os dados coletados representam a percepção dos sujeitos da pesquisa sobre o problema apresentado. Para a realização das entrevistas foi construído um roteiro préestabelecido, com perguntas sobre sua formação e carreira profissional, e também seu entendimento sobre ciências da natureza. As entrevistas foram realizadas em uma sala reservada na própria escola dentro do horário de trabalho dos entrevistados para que não houvesse prejuízo de suas atribuições.

$\mathrm{Na}$ tentativa de preservar a identidade dos sujeitos utilizamos códigos, tais como: Para os professores foram representados de acordo com os códigos: Professores de Biologia (PBIO1, PBIO2, PBIO3), Professores de Física (PFIS1, PFIS2, PFIS3, PFIS4), e Professores de Química (PQUIM1, PQUIM2, PQUIM3, PQUIM4), Para o núcleo gestor, nós os identificamos como (Diretor Escola, Coordenador Pedagógico 1, 2 e ).

A partir das respostas obtidas nos questionários aos professores, tem-se que quase todos os professores de Ciências da Natureza da escola tem Licenciatura na disciplina em que lecionam, exceto um professor de Biologia - graduado em Medicina Veterinária e um professor de Física - graduado em Engenharia Civil.

As entrevistas com os membros do núcleo gestor da escola, por serem considerados potenciais representantes entre a comunidade escolar e a SEDUC/CE, para que tivessem a oportunidade de explicitar de que modo a gestão pode diagnosticar o caso em estudo.

Para o registro dos dados, as entrevistas foram gravadas pela pesquisadora/entrevistadora, com a devida escolha e autorização dos participantes,

\footnotetext{
${ }^{3}$ Entre os sujeitos da pesquisa estão professores de Ciências de Natureza do Ensino Médio da própria escola, dos turnos diurno e noturno, e os professores que estão atualmente exercendo cargos do núcleo gestor da escola (direção e coordenação).
} 
sendo inclusive justificada certa praticidade e otimização na emissão de suas respostas.

Todas as entrevistas foram gravadas em áudio, tendo acontecido em dias diferentes para cada entrevistado. Posteriormente, foi feita a transcrição de cada entrevista e dispostas em quadro elaborado a fim de amparar as análises dos dados.

\section{RESULTADOS E DISCUSSÃO}

Durante o processo de organização dos dados das entrevistas e mapeamento das falas do núcleo gestor (diretor e coordenadores) identificamos aspectos que se relacionavam com o LEC. Esses aspectos definimos como categorias de análise e foram: a estrutura da escola e do laboratório e como os professores utilizam o laboratório. Em função disso, apresentamos os resultados das análises de acordo com cada uma dessas categorias.

\subsection{A Estrutura}

Para Possobom et al. (2003), o laboratório é um local de desenvolvimento do aluno como um todo. Nesse ambiente, durante a realização das atividades práticas e experimentais, são oportunizadas a cooperação, concentração, organização, manipulação de equipamentos, além da vivência da observação de fenômenos, registro de dados, formulação e teste de hipóteses, bem como a elaboração de conclusões entre outros.

Em concordância com o exposto, a coordenação pedagógica e o diretor da escola consideram a importância da realização de atividades práticas e experimentais neste ambiente. O Diretor Escolar afirma ainda que a utilização do laboratório de ciências tem melhorado, no entanto, não como o esperado, ou o adequado.

Eu acredito houve uma melhora a cada ano. É um desafio, por que alguns profissionais às vezes ficam meio restritos na sua disciplina, não querem se envolver muito, às vezes não se sentem motivados ou desafiados. (DIRETOR ESCOLAR, 2019)

Assim, percebe-se que reconhecem a necessidade de melhor adequação do ambiente para que atenda aos padrões atuais de laboratórios escolares que vem sendo instalados pela SEDUC/CE. Além disso, reconhecem também a necessidade de um melhor planejamento, inclusive para a aquisição de itens em falta, de forma a executar as atividades propostas pelos professores. 
Não obstante, o Diretor Escolar cogita que a escola constitui vantagem quando comparada a outras escolas, e que o material ora existente no LEC pode ofertar possibilidades de desenvolvimento de atividades práticas e experimentais, mas que ainda apresenta dificuldades a serem superadas.

Então para quem está à frente do Laboratório de Ciências é um desafio. [...] Mas à vista de outras escolas, nós temos um bom acervo: de microscópios, e de outros equipamentos que podem fazer a diferença no planejamento e na realização das práticas de laboratório. (DIRETOR ESCOLAR, 2019)

Por essa consideração, o Diretor Escolar tende a relacionar a infraestrutura com aparatos e equipamentos, quando evidencia que o fato de o LEC da escola ter microscópio e outros equipamentos já é suficiente para destacar suas possibilidades de utilização.

O desafio enfatizado pelo diretor escolar remete às tentativas de realização de aulas práticas e experimentais no LEC, mas que encontram diversos entraves relacionados à estrutura e ocupação dos espaços da escola, bem como à insuficiência de certos itens necessários à execução das práticas, de acordo com o diretor escolar, que podem desestimular tanto os alunos quanto os professores.

O Coordenador Pedagógico 1, na sua entrevista, também destaca sobre a deficiência estrutural da escola quando menciona que

A gente percebe que muitas vezes o laboratório acaba sendo uma sala de apoio (grifo nosso), pra resolver problemas de logística da escola, então, por uma questão de estrutura, ou de infraestrutura da escola, o laboratório acaba sendo penalizado[...] aquele espaço [...] "desocupado", não sendo usado em "desvio de uso" (grifo nosso)pra outras coisas, mas que esteja ali sendo usado para o que ele se propôs, que é trabalhar com as Ciências, o laboratório de Ciências.[...] E ter estrutura, porque a gente não pode(grifo nosso)... não dá pra viver só de sala de aula. A escola tem que ter algo além da sala de aula, e o local melhor pra isso são os laboratórios. (COORDENADOR PEDAGÓGICO 1, entrevista realizada em abril/2019).

No ano passado [2018], foi muito complicado, porque boa parte do ano foi usado o laboratório como sala de aula (grifo nosso). [...] a barreira das dificuldades de infraestrutura. Mas eu acho que esse ano [2019], ou os próximos anos, vai ser bem mais profícuo no sentido de que o espaço vai estar, pelo menos, acessível. (COORDENADOR PEDAGÓGICO 1, entrevista realizada em abril/2019).

A fala do coordenador revela vários problemas, tais como: desvio da função do laboratório, pouco recurso para manter as instalações da escola como um todo em pleno funcionamento, apontando que um problema na estrutura de uma determinada sala da escola pode interferir numa outra sala, que poderia estar em bom desempenho. 
De acordo com o exposto por Borges (2002), a maneira de organização do LEC interfere na otimização dos resultados. À vista disso, o núcleo gestor da escola assume sua contribuição para que o LEC seja utilizado de maneira mais proveitosa. Essa situação vem tentando ser contornada com uma melhor distribuição e estruturação de outras dependências da escola.

O Coordenador Pedagógico 1 admite ainda que os estudantes precisam de ambiente adequado para a realização de determinadas atividades:

Um espaço mais bem organizado, mais bem projetado também valoriza. $\mathrm{O}$ aluno se sente mais bem acolhido naquele espaço, para que ele possa estudar. (COORDENADOR PEDAGÓGICO1, entrevista realizada em abril/2019).

Como destacado na fala do coordenador, apesar do uso do LEC como sala de aula, desviando sua destinação, isso foi uma tentativa de não desamparar os alunos do seu tempo pedagógico, no entanto, o prejuízo pela falta de aproveitamento dos recursos deste ambiente foi consideravelmente reconhecido.

Eu percebo que, nos últimos anos, o laboratório tem momentos muito bons (gripo nosso), e tem momentos de quase 'inexistência' (grifo nosso), mas isso acontece principalmente por problemas estruturais. Por exemplo, se uma sala de aula tem um problema, o Laboratório de Ciências passa a ser uma sala de aula, então, comprometendo um trabalho que poderia ser melhor desenvolvido nele. [...] Eu acho que falta a gente sentar pra conversar, pra verificar o que é que precisa. Eu acho que a gente tem que fazer primeiro um levantamento do que nós temos com os professores do Laboratório de Ciências, verificar como é que a gente pode melhorar." (COORDENADOR PEDAGÓGICO 2, entrevista realizada em abril/2019).

Novamente foi evidenciada a problemática estrutural, entretanto, não foram descartadas as possibilidades de sua profícua utilização, haja vista que, em anos anteriores, o LEC foi utilizado e percebido com períodos considerados por ele como "muito bons", conforme destaque em grifo, comparando-se com o período estudado.

Logo, existem perspectivas de retomadas da utilização a que o LEC se destina, segundo a fala do Coordenador Pedagógico 2, mesmo que necessite de esforço conjunto do núcleo gestor com o grupo de professores da escola.

Podemos considerar que houve uma proximidade nas respostas dos sujeitos que compõem o núcleo gestor da escola no tocante à importância das atividades práticas e experimentais, e que um dos principais problemas concerne à estrutura física, tanto do LEC quanto da escola como um todo.

O Laboratório de Ciências é muito importante no ensino e aprendizagem [...] e eu acho imprescindível [...] O maior desafio é você conseguir conquistar a participação, o envolvimento dos profissionais, dos professores, além de 
melhorar os equipamentos, e a parte física (grifo nosso). (DIRETOR ESCOLAR, entrevista realizada em abril/2019).

Eu acho que as aulas são fundamentais, é prioridade. [...] A gente vê que muitas vezes o laboratório acaba sendo uma sala de apoio, pra resolver problemas de logística da escola. [...] A gente sabe que os professores têm a boa vontade, mas falta a estrutura (grifo nosso). (COORDENADOR PEDAGÓGICO1, entrevista realizada em abril/2019).

Eu acho que o laboratório e essas experiências das Ciências da Natureza são imprescindíveis. [...] Nossos problemas basicamente têm a ver com a estrutura do Laboratório de Ciências (grifo nosso). (COORDENADOR PEDAGÓGICO2, entrevista realizada em abril/2019).

Então as práticas laboratoriais, ao meu entender, elas são importantíssimas, assim como as aulas de campo no caso da Geografia, que é minha área de atuação. [...] A principal dificuldade diz respeito às questões materiais (grifo nosso). (COORDENADOR PEDAGÓGICO3, entrevista realizada em abril/2019).

No entanto, apesar da infraestrutura do LEC apresentar-se precária, existe a possibilidade de realização de algumas atividades explorando esse ambiente. Mas a realização dessas atividades deixou de ser prioridade frente a outras necessidades da escola, como deficiência estrutural em outros ambientes, sendo o LEC utilizado para suprir tal deficiência sempre que havia possibilidade.

Relacionando-se aos desafios encontrados pelos professores na utilização do LEC, volta-se à estrutura como categoria de suma importância à receptividade dos professores e alunos:

Eu "tô" sendo bem redundante por que os nossos problemas basicamente têm a ver com a estrutura do Laboratório de Ciências (grifo nosso). Por exemplo, eu entrei num Laboratório de Ciências de uma escola em que tinha uma bancada no meio do laboratório e as cadeiras eram todas em volta dessa bancada. Então eu achei muito organizada, eu achei que, na minha visão, eu não entendo de laboratório de Ciências, mas achei que essa seria uma forma de um "laboratório modelo". Então eu acredito que, os desafios que os professores têm é de tentar utilizar, de tentar fazer com que a coisa funcione, mesmo não estando num ambiente adequado; e, mesmo faltando materiais, a gente tentando conseguir materiais alternativos para que os professores consigam utilizar de uma forma mínima o laboratório de Ciências, para conseguir tentar despertar nos alunos os interesses por Química, por Física e por Biologia. Mas, como eu falei, a gente tem problemas, e somente sentando a gente consegue melhorar um pouco, minimizar os problemas que a gente já tem. (COORDENADOR PEDAGÓGICO 2, entrevista realizada em abril/2019).

Nesse sentido, percebemos que o núcleo gestor da escola admite a importância do LEC em ofertar atividades práticas e experimentais, e ainda que seu funcionamento tem sido desviado da função a que se propõe. Também reconhece a necessidade de melhor adequação da estrutura e infraestrutura deste espaço, e ainda buscar nos 
planejamentos proposições de atividades compatíveis com os materiais disponibilizados no LEC.

\subsection{Os Professores}

Nesta seção, apresentamos as análises relativas às considerações observadas nos questionários respondidos pelos professores, e nas falas dos membros do núcleo gestor da escola relacionadas diretamente aos professores. São falas tanto sobre o desenvolvimento quanto sobre os desafios encontrados para a realização de atividades no LEC da escola.

$\mathrm{Na}$ análise dos dados, observamos o interesse de alguns professores em utilizar o laboratório de Ciências para na sua rotina profissional, mas que nessa escola específica, não há tanta disponibilidade. No Quadro 1, percebe-se que alguns professores responderam positivamente quanto à realização de atividades experimentais, mas negativamente quanto ao uso do laboratório de ciências da escola. Respostas negativas também foram registradas no tocante à realização de tais atividades e uso do referido espaço.

Quadro 1 - Distribuição de Professores de Ciências da Natureza do Ensino Médio da escola, por Disciplina e Formação Acadêmica - Ano Letivo de 2019

\begin{tabular}{|c|c|c|c|c|}
\hline O & Professor & Formação & $\begin{array}{c}\text { Realização de atividades } \\
\text { experimentais }\end{array}$ & $\begin{array}{c}\text { Utilização do } \\
\text { laboratório da escola }\end{array}$ \\
\hline \multirow{3}{*}{$\begin{array}{l}\cdot \frac{\pi}{00} \\
\frac{0}{0} \\
\frac{0}{m}\end{array}$} & & $\begin{array}{l}\text { Ciências } \\
\text { Biológicas }\end{array}$ & Não & Não \\
\hline & PBIO2 & $\begin{array}{c}\text { Medicina } \\
\text { Veterinária }\end{array}$ & tia & Sim \\
\hline & $\mathrm{PBIO} 3$ & $\begin{array}{l}\text { Ciências } \\
\text { Biológicas }\end{array}$ & Sim & Sim \\
\hline \multirow{4}{*}{$\cdot \frac{\tilde{\Xi}}{\sqrt{n}}$} & PFIS1 & Física & Sim & Não \\
\hline & PFIS2 & Física & Sim & Não \\
\hline & PFIS3 & Física & Sim & Sim \\
\hline & PFIS4 & Engenharia Civil & Sim & Sim \\
\hline \multirow{4}{*}{ 导 } & PQUIM1 & Química & Não & Não \\
\hline & PQUIM2 & Química & Não & Não \\
\hline & PQUIM3 & Química & Sim & Não \\
\hline & PQUIM4 & Química & Sim & Sim \\
\hline
\end{tabular}

Fonte: Elaborado pela professora-pesquisadora

Os professores têm em sua atividade profissional uma complexidade de situações, desde a preocupação consigo próprio, perpassando pela discrepância entre os ideais e as realidades do cotidiano da escola, provocação à "transmissão de 
conhecimentos", dificuldades com alunos que criam problemas, até o material didático insuficiente (HUBERMAN, 2000, p. 39). Então, o desenvolvimento de atividades práticas pode ser percebido por parte de alguns profissionais como objeto de mudança, mais uma obscuridade a ser contornada, indicando difícil adaptação.

A escola tem buscado a construção coletiva de ações, de forma a proporcionar a todos os seus professores a oportunidade de tentar superar as dificuldades encontradas nas transformações da demanda escolar.

\begin{abstract}
Aquela oportunidade de construir práticas com os professores das disciplinas de Matemática, de Química, de Física, de Biologia. É um desafio (grifo nosso), por que alguns profissionais às vezes ficam meio restritos na sua disciplina, não querem se envolver muito, às vezes não se sentem motivados ou desafiados. (DIRETOR ESCOLAR, entrevista realizada em abril/2019).
\end{abstract}

O pouco envolvimento citado na fala do Diretor Escolar foi reafirmado na colocação do Coordenador Pedagógico 3, ao descrever sua avaliação do uso do LEC da escola nestes últimos anos:

Nós temos que avaliar questões internas mesmo, de planejamento dos nossos colegas professores, do porquê não utilizar com tanta frequência, do porquê que não gostam de usar. (COORDENADOR PEDAGÓGICO 3, entrevista realizada em abril/2019).

A trajetória do trabalho do professor da Educação Básica, principalmente do Ensino Médio, tem se apresentado de maneira pouco modificada em comparação com décadas anteriores, com componentes que ainda se mantém no decurso dos anos, como o plano administrativo, as normas, as organizações do trabalho (HUBERMAN, 2000, p. $55)$.

As existências de aspectos de perfis relacionados à sobrevivência ou à descoberta são experimentadas concomitantemente, podendo se verificar um desses perfis como dominante. Expõe-se ainda perfis com outras características tais como a indiferença, a frustação, mas também a serenidade (HUBERMAN, 2000, p.39). Então, se o profissional se vê provisoriamente naquela incumbência, ou não tem motivação no prosseguimento da carreira, podem ser percebidas consequências do comprometimento inadequado.

Os profissionais da escola não têm caráter uniforme. Na mesma unidade escolar tem-se professores com perfis diferentes, ainda que pertencentes a uma mesma equipe de trabalho. Quando indagado sobre a relevância e como vem se desenvolvendo a realização das atividades experimentais na referida escola, nas respostas combinadas, percebe-se perfis de descoberta, com dedicação e prestatividade, bem como perfis de resistência e desinteresse: "A gente sabe que os professores têm a boa vontade, mas falta a estrutura. [...] A primeira barreira é a de adesão dos próprios colegas." (COORDENADOR PEDAGÓGICO 1, grifo nosso, entrevista realizada em abril/2019). 
Julga-se pertinente uma reflexão da prática docente para o sucesso de mudanças ainda não experimentadas nas metodologias. Cachapuz et al. (1989) considera na formação dos docentes uma oportunidade de contemplação no que tange às atividades experimentais relacionados ao processo de ensino e aprendizagem. Tal importância foi relatada no comentário tecido pela coordenação pedagógica da escola.

Eu acho que, primeiro, nós precisamos de algum tipo de formação, de capacitação (grifo nosso). De alguém que dê uma capacitação para os professores, não necessariamente para os professores que são coordenadores, mas para os outros professores, no sentido de sensibilizar ou entender da importância da experiência, do experimento, da experimentação dentro do laboratório. E envolver os alunos e o professor, no sentido de sensibilizar através do conhecimento, da compreensão. Que esses professores se irmanem, se apoiem à adesão ao trabalho dos professores coordenadores do laboratório. (COORDENADOR PEDAGÓGICO 1, entrevista realizada em abril/2019).

A necessidade de momentos propícios para uma formação em serviço relacionada à realização de atividades práticas e experimentais foi destacada pelo núcleo gestor. Os professores precisam de momentos de estudo para diversificar e aprimorar os seus materiais didáticos, seus critérios de avaliação, a disposição dos alunos no ambiente de aprendizagem, fase caracterizada por Huberman (2000) como diversificação.

Eu acho que, primeiro, inserir no nosso corpo docente a cultura de utilização do laboratório. Eu acho que isso é muito importante. E, ao mesmo tempo que é muito importante, é bastante desafiador, por que você está trabalhando com algo que é cultural. Então estimular a utilização, eu acho que é um ponto nodal nesse processo. Segundo, planejar, realizar junto, coordenação junto aos professores responsáveis (grifo nosso), os tutores pelo LEC, realizar um planejamento mais efetivo, melhor pensado. [...] Uma frente de conscientização, que é a frente mais subjetiva, uma frente mais logística, de planejamento e realização das atividades, (COORDENADOR PEDAGÓGICO 3, entrevista realizada em abril/2019).

Essa colocação explana o que Galiazzi et al. (2001) aponta referindo-se à resistência do desenvolvimento do trabalho como fator que pode implicar nas possibilidades de aprendizagem.

Mas precisa melhorar muito, no sentido de formação continuada (grifo nosso) para os professores, [...]até os professores talvez por uma forma de falta de formação, realmente mais voltada para o lado pedagógico, ficamos ainda no tradicional. (COORDENADOR PEDAGÓGICO 1, entrevista realizada em abril/2019).

Quando Borges (2002) trata o laboratório por sua relevância na aprendizagem, traz também seus objetivos relacionados à sua relevância e organização para otimização 
dos resultados. Quando perguntados sobre esta relevância, os gestores posicionam-se como articuladores no desenvolvimento do trabalho dos professores.

Eu acredito que a gestão, pode contribuir na medida que ela estimula, aos professores coordenadores de área o planejamento e a utilização mais sistemática dessa ferramenta (grifo nosso). Então, durante o planejamento anual, o planejamento mensal, é importante estar ali, reforçando a importância do professor planejar aulas que envolvam, que utilizem o Laboratório de Ciências, seja da Matemática, da Física, da Química ou da Biologia. (DIRETOR ESCOLAR, entrevista realizada em abril/2019).

No entanto, há uma necessidade dessa articulação ser de fato efetivada, enfatizando que apenas o planejamento que já vem sendo conduzido não está sendo suficiente para o bom aproveitamento do LEC.

É sentar com os professores, verificar quais são as dificuldades, e tentar sanar essas dificuldades com planejamento (grifo nosso), ouvindo os professores, ouvindo o que é necessário, eu acho que isso já minimizaria muita coisa. (COORDENADOR PEDAGÓGICO2, entrevista realizada em abril/2019).

A fala do Coordenador Pedagógico 2 remete à necessidade de identificação das dificuldades dos professores, a serem levantadas no plano de ação educacional, relevantes para estruturar a formação voltada para as atividades práticas e experimentais.

Em resposta à mesma indagação, e reforçando a conexão da gestão escolar junto aos professores, acrescenta-se ainda o que Galiazzi et al. (2001) atenta para os objetivos das atividades experimentais, dialogando aqui com atributos relativos à motivação.

\begin{abstract}
Eu acho que a coordenação pode contribuir tanto num "up", tanto nos nossos colegas professores, quanto nos nossos alunos, tentando mostrar para ambos a importância das práticas laboratoriais como ferramenta fundamental e importantíssima do processo de ensino e aprendizagem, [...] Então eu acho que um ponto chave é que a coordenação, a gestão de uma forma geral, possa jogar com essas ideias de maneira clara, de maneira transparente, democrática, ao corpo de professores e alunos, para que nós possamos nos sentir entusiasmados em utilizar essas práticas como ferramenta importante. (COORDENADOR PEDAGÓGICO3, entrevista realizada em abril/2019).
\end{abstract}

Indagados sobre os desafios que os professores da escola encontram quando usam o LEC, uma colocação marcante é no tocante à escassez de insumos. Não obstante, foi identificada também a necessidade de otimização dos planejamentos, para que o trabalho seja desenvolvido dentro de um bom gerenciamento.

Então a gente tem que fazer assim: um planejamento junto com os professores pra ver o que é que se usa (grifo nosso), o que é que realmente se precisa, pra não comprar coisas que ficam lá paradas, enquanto o que 
realmente eles precisam não é comprado. Assim a gente tem que ter esse planejamento junto com os professores. Isso faz a diferença na gestão. (COORDENADOR PEDAGÓGICO 1, entrevista realizada em abril/2019).

Mais uma vez, o viés do planejamento das atividades propostas torna pertinente, haja vista que o LEC possui materiais a serem utilizados, caracterizando a sua possibilidade de uso, não deixando que alguns entraves detenham seu aproveitamento.

Então eu acredito que os desafios que os professores têm é de tentar utilizar, de tentar fazer com que a coisa funcione, mesmo não estando num ambiente adequado; e, mesmo faltando materiais, a gente tentando conseguir materiais alternativos para que os professores consigam utilizar de uma forma mínima o laboratório de Ciências, para conseguir tentar despertar nos alunos os interesses por Química, por Física e por Biologia. Mas, como eu falei, a gente tem problemas, e somente sentando a gente consegue melhorar um pouco, minimizar os problemas que a gente já tem. (COORDENADOR PEDAGÓGICO 2, entrevista realizada em abril/2019).

Volta-se à ilustração de Cachapuz et al. (1989) sobre a notoriedade do professor dada às atividades experimentais, para que encontre conformidade com o caráter motivacional dos estudantes.

Eu acho que os professores não se sentem também tão entusiasmados em virtude de às vezes a receptividade dos alunos não ser tão empolgante quanto se esperava. Então acho que esses dois pontos são cruciais. Pelo menos é o que eu sinto quando eu vejo determinados comentários na própria sala dos professores, em que os colegas levam, só que os meninos me parece que não se interessam muito por aquilo. Aí nós temos que avaliar também [...] se foi a metodologia que não chegou de maneira eficaz; (COORDENADOR PEDAGÓGICO 3, entrevista realizada em abril/2019).

A partir das análises, percebemos que o núcleo gestor da escola percebe que os professores da área de Ciências da Natureza possuem uma compreensão da importância das aulas experimentais para processo de ensino e aprendizagem, oportunizando aulas mais significativas para os estudantes.

\section{CONSIDERAÇÕES}

A escola em questão pode ser caracterizada antiga, mas mantém em suas instalações materiais e equipamentos que compõem um laboratório de ciências, dentre seus outros ambientes. Isso já é uma premissa para a possibilidade de realização de atividades experimentais nesse ambiente.

Os professores apontaram principalmente obstáculos de cunho estrutural e de tempo hábil. Mas, mesmo assim utilizam esse espaço para desenvolver atividades experimentais. Em relação a estrutura, consideramos as potencialidades do laboratório de ciências que podem ser utilizadas no processo de ensino e aprendizagem. Outro 
aspecto relevante é a respeito do caráter motivacional das atividades propostas a serem realizadas no laboratório de ciências, devendo estas serem incentivadoras, tanto para os alunos, quanto para os professores.

Pelas entrevistas realizadas, verificamos que o núcleo gestor da escola tem empenhado esforços voltados a suprir necessidades estruturais da escola, inclusive dando importância a itens para o laboratório de ciências. Todavia, ainda foram citadas deficiências na estrutura da escola como um todo, as quais tomam o espaço destinado ao referido laboratório como uma sala de aula, ainda que em caráter emergencial. Em tempo, a sua disposição, inadequada para sala de aula tradicional, provoca insatisfação para o grupo de professores da escola. Também foram colocados pelo núcleo gestor aspectos pertinentes à necessidade de melhorias nos planejamentos, neste caso, os coletivos semanais.

Destarte, atentamos para a realização de formações voltadas à realização de atividades práticas e experimentais. As formações deverão ser realizadas nos horários de planejamento coletivo, momento em que definir-se-á em quais aulas haverá intervenções com as atividades elencadas juntamente com os professores.

Acreditamos que esta pesquisa, assim como a proposta de formação, implica em trazer aspectos de valorização dos planejamentos e de sua profícua execução, incentivando os professores das Ciências da Natureza a refletirem também sobre a sua formação enquanto sujeitos do aprendizado.

Isso posto, poderemos pensar numa visão mais adiante, investigando de que forma as atividades propostas a serem realizadas nos laboratórios de ciências poderão se relacionar com as outras áreas do conhecimento.

Empenha-se ainda a oportunidade de melhoria da práxis pedagógica ligada ao laboratório de ciências, bem como motivações para o desenvolvimento de atividades correlatas naquele ambiente. Outrossim, tal proposta poderá ainda ser oportuna para outras escolas que identificarem semelhanças na sua problemática cotidiana.

\section{REFERÊNCIAS}

BASSOLI, F. Atividades práticas e o ensino-aprendizagem de ciência(s): mitos, tendências e distorções. Ciência \& Educação, Bauru - SP, vol. 20, n. 3, pp. 579-593, 2014. 
BLOSSER, P. E.; MATÉRIAS EM PESQUISA DE ENSINO DE FÍSICA: O PAPEL DO LABORATÓRIO NO ENSINO DE CIÊNCIAS. Caderno Catarinense de Ensino de Física. Florianópolis, v.5 (2), p. 74-78, ago. 1988.

BLOSSER, Patrícia E. Matérias em pesquisa de ensino de física: o papel do laboratório no ensino de ciências. Caderno Catarinense de Ensino de Física. Florianópolis, 5 (2): p. 74-78, ago. 1988.

BOGDAN, Roberto C., BIKLEN, Sari K. Investigação qualitativa em educação. Porto Editora, 1994.

BORGES, A. T. Novos rumos para o laboratório escolar de ciências. Caderno Brasileiro de Ensino de Física. Santa Catarina, v.19, n.13, p. 291-313, dez. 2002.

CACHAPUZ, A. et al. O Trabalho Experimental nas aulas de Física e Química: Uma perspectiva nacional. Gazeta de Física, Sociedade Portuguesa de Física, Lisboa - PT, vol. 12, Fasc. 2, pp 65-69, abr. 1989.

GALIAZZI, M. C.; ROCHA, J. M. B. ; SCHMITZ, L. C.; GIESTA, S. M.;

GONÇALVES, F. P. . Objetivos das atividades experimentais no ensino médio: a pesquisa coletiva como modo de formação de professores de Ciências. Ciência e Educação (UNESP), Bauru, v. 7, n.2, p. 249-263, 2001.

GONÇALVES, F. P.; MARQUES C. A. Contribuições pedagógicas e epistemológicas em textos de experimentação no ensino de química. Revista Investigações em Ensino de Ciências, v. 11(2), pp. 219-238, 2006.

Gonçalves, Francisca Helen Cardoso. A Utilização do Laboratório de Ensino de Ciências pelos professores de Ciências da Natureza da Escola de Ensino Fundamental e Médio Heráclito de Castro e Silva. Dissertação (mestrado profissional) - Universidade Federal de Juiz de Fora, Faculdade de Educação/CAEd. Programa de Pós Graduação em Gestão e Avaliação da Educação Pública, 2019.

GOUVEIA, RAIMUNDO VALCEMIR SABÓIA. As atividades práticas e experimentais no ensino de ciências da natureza no ensino médio em uma escola estadual do Amazonas. Dissertação (mestrado profissional) - Universidade Federal de Juiz de Fora, Faculdade de Educação/CAEd. Programa de Pós Graduação em Gestão e Avaliação da Educação Pública. P. 92. 2017.

HUBERMAN, M. O ciclo de vida profissional dos professores. In: NÓVOA, A.(org.) Vidas de professores. Portugal: Porto Editora, $2^{a}$ edição, 2000, p. 31-61.

LEITE, J. C.; RODRIGUES, Maria Aparecida ; MAGALHÃES JÚNIOR, Carlos Alberto de Oliveira . Ensino Investigativo: análise de sequências didáticas produzidas por professores(as) de Ciências em um contexto de formação continuada. Revista Insignare Scientia (RIS), v. 2, p. 43-61, 2019.

LÜDKE, Menga, ANDRÉ, Marli E. D. A., Pesquisa em educação: abordagens qualitativas. São Paulo: EPU, 1986.

POSSOBOM, C. C. F.; OKADA, F. K.; DINIZ, R. E. S. Atividades práticas de laboratório no ensino de Biologia e de Ciências: relato de uma experiência. In: GARCIA, W. G.; GUEDES, A. M. (Orgs.). Núcleos de ensino. São Paulo: Unesp, PróReitoria de Graduação, p. 113-123, 2003.

THOMAZ, Marília Fernadez. A experimentação e a formação de professores de ciências: uma reflexão. Caderno Catarinense de Ensino de Física. Florianópolis, v. 17, n. 3, p. 360-369, dez, 2000. 